\title{
Coal-fired thermal power plant performance optimization using Markov and CFD analysis
}

\author{
Pardeep Kumar ${ }^{1} \cdot$ Ansar Ali $^{1}$ · Sandeep Kumar ${ }^{1}$
}

Received: 6 August 2019 / Accepted: 8 January 2020 / Published online: 18 January 2020

(c) Springer Nature Switzerland AG 2020

\begin{abstract}
In the present stimulated business environment, power sector is playing a major role in the economic growth of India. During the last 20 years, the country had been facing a poor supply of energy and this supply-demand gap is increasing continuously. Therefore, it is important for power plants to improve its power generation capacity drastically by reducing the failure rate. In the present paper, to analyze the causes of poor availability, thermal power plant has divided into six different systems and a system comprising waste gases heating system has been considered. With the help of transition diagram, mathematical equations have been used to find out the availability. After analyzing, it was found that the value of availability is very low and boiler tube failure is one of the most critical factors for this low availability of system. The power plants have low availability causing serious concern and need to identify the responsible factors for this low availability. Boiler tube failure is identified as a responsible factor for low availability, and economizer is the zone where maximum failure occurred. From the maintenance history sheet, it was identified that economizer is a critical zone where maximum tube failures occur and the main cause of economizer failure is due to high-velocity flue gas particle, i.e., erosion. To increase the availability and minimize the failures, erosion process must be reduced in economizer tubes which is mainly responsible for economizer failure and then CFD analysis has been done for this purpose. This results in a decrease in the shutdown period of the plant and an increase in the system availability as well as the power of the system.
\end{abstract}

Keywords Performance analysis · Thermal power plant · Availability · Mathematical modeling $\cdot$ Markov birth-death process

\section{Introduction}

In today's competitive world, it becomes necessary that thermal power plant will be available for long run without any failure. In India, total installed capacity of electricity generation is $330,354 \mathrm{MW}$ while total thermal installed capacity is $220,456 \mathrm{MW}$, i.e., $66.8 \%$ of the total installed capacity (refer Table 1). The major contribution almost $59 \%$ in thermal installed capacity is coal-fired thermal power plant. For continuous power production, boiler becomes the backbone of a thermal power plant. Boiler tube failure is one of the critical problems which are facing the thermal power plant and influence the rate of power generation. This loss of generation increases the operating cost of plant, and a significant amount of water is being waste. Availability analysis gives the necessary information about various parameters of the system. A brief literature review about reliability, availability and maintainability is as follows:

Cherry et al. [1] explained the analysis of reliability by measuring long-run cycle availability of a chemical industry. Dai et al. [2] performed both reliability and availability analyses for some different complex systems. Gupta et al. $[3,4]$ discussed performance modeling using probabilistic approach and developed Markov model for performance evaluation of a system of coal handling of a thermal power

Pardeep Kumar, pardeepkamboj@yahoo.com | ${ }^{1}$ Meerut Institute of Engineering and Technology, Meerut, Uttar Pradesh, India. 
Table 1 Installed capacity for different sources of fuel

\begin{tabular}{lcc}
\hline Fuel used & Installed capacity (MW) & \% of total \\
\hline Total thermal & 220,456 & 66.8 \\
Coal & 194,433 & 58.9 \\
Gas & 25,185 & 7.6 \\
Oil & 838 & 0.3 \\
Hydro & 44,614 & 13.5 \\
Nuclear & 6780 & 2.1 \\
Renewable energy sources & 58,303 & 17.7 \\
Total & 330,354 & \\
\hline
\end{tabular}

plant. Gupta et al. [5] examined soap production system and flexible powder polymer production system in a soap plant. Gupta et al. [4] discussed Mathematical formulation for reliability analysis in terms of availability of a critical ash handling system. Kumar [6] have done availability analysis using Markov approach of air circulation system. Khanduja [7] framed out a mathematical model with the help of mathematical analysis, and the value of steadystate availability was derived for analysis of system availability of bleaching unit in a paper plant. Lai [8] obtained the availability of steady state for the system of distributed software/hardware with the help of Markov model. Kumar
[9] applied Six Sigma approach to reduce the causes and improve the performance of a coal-fired thermal power plant. Kumar [10, 11] suggested maintenance policy for a different system of a power plant. Sabouhi et al. [12] discussed the reliability modeling and availability analysis of combined cycle power plants (CCPP). Yadav [13] derived equations with the help of Markov model.

\section{Availability analysis of waste gases system of a thermal power plant}

The flow diagram of thermal power plant consisting of waste gases system (refer Fig. 1) shows that flue or waste gases from furnace flow upward and this waste heat is utilized in superheater, economizer and air preheater to raise the temperature of some extent of steam, feed water and air. To find the availability, this system is divided further in four different subsystems.

Subsystem A It consists of furnace, superheater, economizer and air preheater and arranged in series to establish a single subsystem.

Subsystem $B$ It consists of two electrostatic precipitators (ESP) which make a single subsystem.
Fig. 1 Flow diagram of thermal power plant

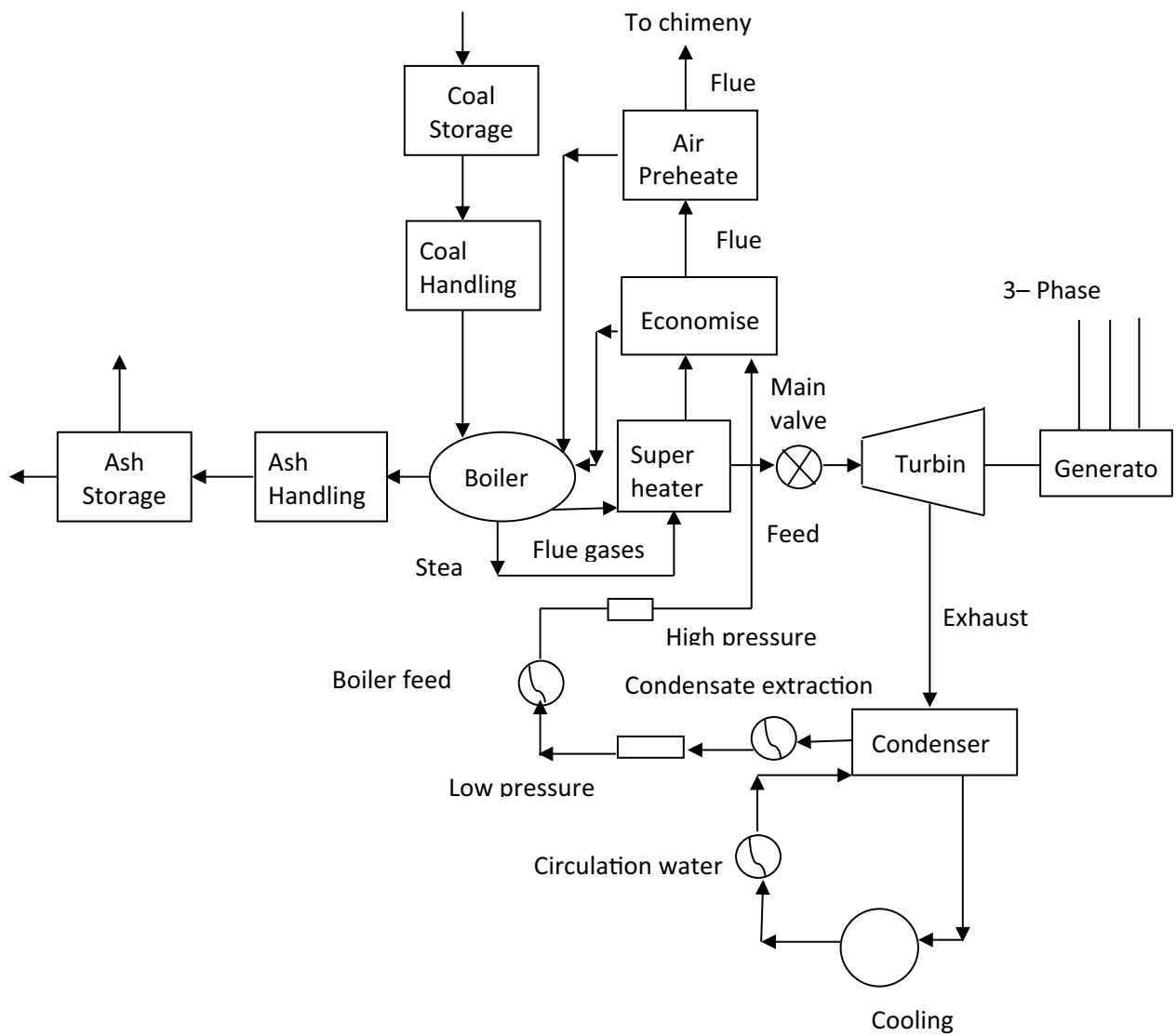


Subsystem C Two forced draft fans working in parallel consist of a subsystem.

Subsystem DThree induced draft fans (ID fan) arranged in parallel create one subsystem.

Table 2 shows some notations which are used to construct the transition diagram as shown in Fig. 2.

\subsection{Performance modeling of waste gases system}

The mathematical equations are derived using Chapman-Kolmogorov equation with the help of transition diagram.

$$
P_{0}^{\prime}(t)+\sum_{i=1}^{4} \lambda_{i} P_{0}(t)=\beta_{1} P_{12}(t)+\beta_{2} P_{6}(t)+\beta_{3} P_{3}(t)+\beta_{4} P_{1}(t)
$$

$$
\begin{aligned}
P_{1}^{\prime}(t) & +\sum_{i=1}^{4}\left(\lambda_{i}+\beta_{4}\right) P_{1}(t) \\
= & \beta_{1} P_{11}(t)+\beta_{2} P_{7}(t)+\beta_{3} P_{4}(t)+\beta_{4} P_{2}(t)+\beta_{4} P_{0}(t)
\end{aligned}
$$

$$
\begin{aligned}
P_{2}^{\prime}(t) & +\sum_{i=1}^{4}\left(\lambda_{i}+\beta_{4}\right) P_{2}(t) \\
= & \beta_{1} P_{10}(t)+\beta_{2} P_{8}(t)+\beta_{3} P_{5}(t)+\beta_{4} P_{9}(t)+\beta_{4} P_{1}(t)
\end{aligned}
$$

Full-capacity states (without standby)
$\begin{aligned} & \text { One unit of subsystem } \mathrm{A}_{1} \text { and } \mathrm{A}_{3} \text { is in failed state, and the system is working in full } \\ & \text { capacity with standby unit }\end{aligned}$
$\begin{aligned} & \mathrm{A}_{1}, \mathrm{~A}_{4}, \mathrm{~A}_{5}, \mathrm{~A}_{6} \text { and } \mathrm{A}_{3}{ }^{*} \\ & \text { Failed states } \\ & \text { Reduced capacity states } \\ & \text { Failure rates } \\ & \text { Repair rates } \\ & \text { System working at full capacity }\end{aligned}$
System working at reduced capacity
System in failed state

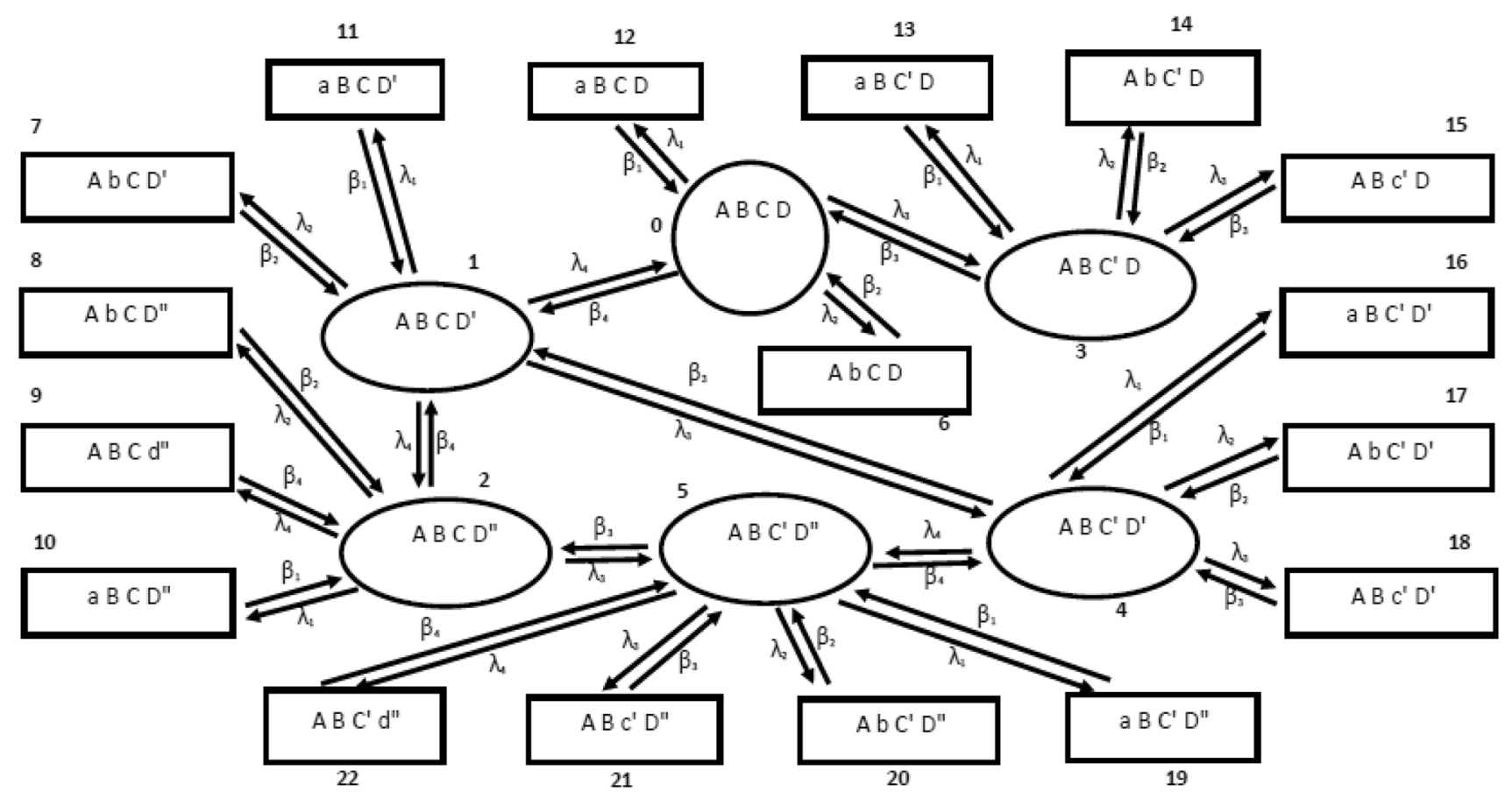

Fig. 2 Transition diagram of waste gases heating system 


$$
P_{3}^{\prime}(t)+\sum_{i=1}^{4}\left(\lambda_{i}+\beta_{3}\right) P_{3}(t)=\sum_{i=1}^{3} \beta_{i} P_{i-18}(t)+\lambda_{3} P_{0}(t)+\beta_{4} P_{4}(t)
$$$$
P_{4}^{\prime}(t)+\sum_{i=1}^{4}\left(\lambda_{i}+\beta_{3}+\beta_{4}\right) P_{4}(t)
$$$$
=\sum_{i=1}^{3} \beta_{i} P_{i-15}(t)+\lambda_{33} P_{1}(t)+\lambda_{4} P_{3}(t)+\beta_{4} P_{5}(t)
$$

$P_{5}^{\prime}(t)+\sum_{i=1}^{4}\left(\lambda_{i}+\beta_{4}+\beta_{3}\right) P_{5}(t)=\sum_{i=1}^{4} \lambda_{i} P_{i-12}(t)+\lambda_{4} P_{4}(t)+\lambda_{3} P_{2}(t)$

$$
P_{i}^{\prime}(t)+\beta_{m} P_{i}(t)=\lambda_{m} P_{j}(t)
$$

$$
m=1 \text {, then } i=12, j=0 ; i=11, j=1, i=10 \text {, }
$$$$
j=2 ; i=13, j=3 ; i=16, j=4 ; i=19, j=5 \text {; }
$$$$
m=2 \text {, then } i=6, j=0 ; i=7, j=1 ; i=8 \text {, }
$$$$
j=2 ; i=14, j=3 ; i=17, j=4 ; i=20, j=5
$$$$
m=3 \text {, then } i=15, j=3 ; i=18, j=4, i=21, j=5
$$$$
m=4 \text {, then } i=9, j=2 ; i=22, j=5
$$

\subsection{Steady-state availability of waste gases system}

By putting derivatives $=0$ as $t \rightarrow \infty$ in Eqs. 1 to 7 and solved by recursive method, the following values obtained of all 23 state probabilities $\left(P_{0}\right.$ to $\left.P_{22}\right)$ in terms of full working state probability, i.e., $P_{0}$. where

$$
\begin{array}{llll}
C_{1}=\lambda_{3}+\beta_{4} & C_{5}=\lambda_{4}+\beta_{3}+\beta_{4} & C_{8}=\frac{\lambda_{4} C_{6}}{C_{3} C_{6}-\lambda_{3} \beta_{3}} & C_{12}=C_{9} C_{11}+C_{10} \\
C_{2}=\lambda_{3}+\lambda_{4}+\beta_{4} & C_{6}=\beta_{3}+\beta_{4} & C_{9}=\frac{\lambda_{3}+C_{7} \beta_{4}}{C_{3}-\beta_{4} C_{8}} & C_{13}=C_{7} C_{11}+C_{8} C_{12} \\
C_{3}=\lambda_{3}+\beta_{4} & C_{7}=\frac{\lambda_{4} \beta_{3}}{C_{3} C_{6}-\lambda_{3} \beta_{3}} & C_{10}=\frac{\lambda_{4}}{C_{2}-\beta_{4} C_{8}} & C_{14}=\frac{C_{11} \beta_{4}+\lambda_{3}}{C_{4}} \\
C_{4}=\lambda_{4}+\beta_{3} & C_{11}=\frac{C_{3} C_{4}-\lambda_{3} \beta_{3}-C_{10} C_{4} \beta_{4}}{\beta_{3} \beta_{4}-C_{9} C_{4} \beta_{4}} & C_{15}=\frac{C_{13} \lambda_{3}+C_{11} \lambda_{4}}{C_{6}}
\end{array}
$$

Hence,

$A v=P_{0}+P_{1}+P_{2}+P_{3}+P_{4}+P_{5}$

$A v=P_{0}\left(1+C_{11}+C_{12}+C_{13}+C_{14}+C_{15}\right)$

Table 3 shows the variation of system availability with different possible combinations of failure and repair rates for waste gases heating system. System availability decreases $(0.9402-0.7985)$ appreciably by $14.2 \%$ with an increase in the failure rate from 0.005 (once in $200 \mathrm{~h}$ ) to 0.040 (once in $25 \mathrm{~h}$ ). Similarly, other values show the decreasing trend of availability. Correspondingly, repair rate also affects the value of availability; as repair rate increases from 0.10 (once in $10 \mathrm{~h}$ ) to 0.50 (once in $2 \mathrm{~h}$ ), the system availability increases $(0.9784-0.9402)$ drastically by $3.82 \%$.

This table also shows that the failure rate influences the availability of the system. System availability can be improved by decreasing the failure rate. Maintenance data show that boiler tube failure is one of the most critical reasons for low availability of waste gases heating system.

Data of boiler tube failures of the last 10 years for waste gases heating system of a thermal power plant in

$$
\begin{aligned}
& P_{1}=C_{12} P_{0} \quad P_{2}=C_{13} P_{0} \quad P_{3}=C_{14} P_{0} \quad P_{4}=C_{11} P_{0} \quad P_{5}=C_{15} P_{0} \quad P_{6}=\frac{\phi_{2}}{\lambda_{2}} P_{0} \\
& P_{7}=\frac{\phi_{2}}{\lambda_{2}} C_{12} P_{0} \quad P_{8}=\frac{\phi_{2}}{\lambda_{2}} C_{13} P_{0} \quad P_{9}=\frac{\phi_{4}}{\lambda_{4}} C_{13} P_{0} \quad P_{10}=\frac{\phi_{1}}{\lambda_{1}} C_{13} P_{0} \quad P_{11}=\frac{\phi_{1}}{\lambda_{1}} C_{12} P_{0} \quad P_{12}=\frac{\phi_{1}}{\lambda_{1}} P_{0} \\
& P_{13}=\frac{\phi_{1}}{\lambda_{1}} C_{14} P_{0} \quad P_{14}=\frac{\phi_{2}}{\lambda_{2}} C_{14} P_{0} \quad P_{15}=\frac{\phi_{3}}{\lambda_{3}} C_{14} P_{0} \quad P_{16}=\frac{\phi_{1}}{\lambda_{1}} C_{11} P_{0} \quad P_{17}=\frac{\phi_{2}}{\lambda_{2}} C_{11} P_{0} \quad P_{18}=\frac{\phi_{3}}{\lambda_{3}} C_{11} P_{0} \\
& P_{19}=\frac{\phi_{1}}{\lambda_{1}} C_{15} P_{0} \quad P_{20}=\frac{\phi_{2}}{\lambda_{2}} C_{15} P_{0} \quad P_{21}=\frac{\phi_{3}}{\lambda_{3}} C_{15} P_{0} \quad P_{22}=\frac{\phi_{4}}{\lambda_{4}} C_{15} P_{0}
\end{aligned}
$$

The probability of full working capacity, namely $P_{0}$ determined by using normalizing condition: i.e., (sum of the probabilities of all working states, reduced capacity and failed states is equal to 1) $\sum_{i=0}^{22} P_{i}=1$; therefore,
Haryana state have been collected and analyzed as shown in Table 4. Four main factors identified are responsible for tube failures such as boiler wall, economizer, superheater

$P_{0}=\frac{1}{\left[\left(1+C_{11}+C_{12}+C_{13}+C_{14}+C_{15}\right)\left(1+\left(\frac{\lambda_{1}}{\beta_{1}}+\frac{\lambda_{2}}{\beta_{2}}\right)+\frac{\lambda_{3}}{\beta_{3}}\left(C_{11}+C_{14}+C_{15}\right)+\frac{\lambda_{4}}{\beta_{4}}\left(C_{14}+C_{15}\right)\right)\right]}$ 
Table 3 Availability matrix for waste gases heating system

\begin{tabular}{|c|c|c|c|c|c|c|}
\hline \multirow[t]{2}{*}{$\lambda_{1}$} & \multicolumn{6}{|l|}{$\beta_{1}$} \\
\hline & 0.1 & 0.2 & 0.3 & 0.4 & 0.5 & Constant values \\
\hline 0.005 & 0.9402 & 0.9596 & 0.9676 & 0.9712 & 0.9784 & \multirow{5}{*}{$\begin{array}{l}\lambda_{2}=0.010, \beta_{2}=0.20 \\
\lambda_{3}=0.0033, \beta_{3}=0.25 \\
\lambda_{4}=0.005, \beta_{4}=0.20 \\
\lambda_{33}=0.004, \mu_{33}=\mathbf{0 . 3 0}\end{array}$} \\
\hline 0.0066 & 0.9298 & 0.9424 & 0.9639 & 0.9701 & 0.9731 & \\
\hline 0.0100 & 0.9192 & 0.9322 & 0.9412 & 0.9565 & 0.9698 & \\
\hline 0.020 & 0.9085 & 0.9408 & 0.9533 & 0.9599 & 0.9653 & \\
\hline 0.040 & 0.7985 & 0.9164 & 0.9398 & 0.9492 & 0.9619 & \\
\hline
\end{tabular}

Table 4 Data history sheet of boiler tube failure

\begin{tabular}{lllllll}
\hline Sr. no. & Year & $\begin{array}{l}\text { Total boiler } \\
\text { failure }\end{array}$ & Wall failure & $\begin{array}{l}\text { Economizer } \\
\text { failures }\end{array}$ & $\begin{array}{l}\text { Superheater } \\
\text { failures }\end{array}$ & $\begin{array}{l}\text { Reheater } \\
\text { failures }\end{array}$ \\
\hline 1 & $2007-2008$ & 14 & 4 & 0 & 5 & 4 \\
2 & $2008-2009$ & 13 & 3 & 8 & 2 & 0 \\
3 & $2009-2010$ & 7 & 3 & 2 & 1 & 0 \\
4 & $2010-2011$ & 18 & 4 & 6 & 5 & 3 \\
5 & $2011-2012$ & 11 & 2 & 4 & 3 & 2 \\
6 & $2012-2013$ & 22 & 1 & 12 & 5 & 4 \\
Total & & 85 & 17 & 32 & 21 & 13 \\
\hline
\end{tabular}

and reheater, and it was found that about $37 \%$ of tube failures take place in economizer.

\subsection{Root cause of economizer failure}

Installation of new thermal power plants is very difficult because it requires a high investment cost and considerable time. The power plants have low availability causing serious concern and need to identify the responsible factors for this low availability. Boiler tube failure is identified as a responsible factor for low availability, and economizer is the zone where maximum failure occurred. The feed water is fed into the boiler drum through the economizer. It is placed in the path of flue gases so that heat can be transferred from gases to feed water and can increase the efficiency of boiler.

It was found from the literature and data history sheets of thermal power plants that economizer is a critical zone where maximum tube failures occur and the main cause of economizer failure is due to high-velocity flue gases particle, i.e., erosion. Erosion is a process in which metal is eroded and removed by the impingement of particle from the surface of any material. The rate of erosion depends on some variables such as particle velocity, angle of impingement, size, shape and hardness. So, many factors are responsible for erosion, but one most important factor which affects more is velocity and can be written as

Erosion $=R \times$ (Velocity) $n$, where $n$ is exponent of velocity and $R$ is assumed as a constant value which depends on angle, size and other factors.
Economizer is arranged in two groups having bare coil tubes with an outer diameter of $51 \mathrm{~mm}$, and material is SA $210 \mathrm{C}$. There are 133 rows of coil tubes wound all together, and each row is made up of 3 parallel coil sleeves, arranged in line with horizontal pitch of $120 \mathrm{~mm}$ and vertical pitch of $102 \mathrm{~mm}$. The 3-D geometrical models of economizer have been designed with the help of SOLIDWORKS and CATIA design tool as per the specified dimensions. These geometrical details have been taken from available drawings and literature.

The CFD analysis is divided into three parts as:

A. CFD modeling of economizer.

B. Present flue gases flow distribution in economizer.

C. Flow distribution of flue gases in economizer with baffle plates.

The model of economizer was drawn as shown in Figs. 3 and 4, taking all the dimensions from the actual geometry of the thermal power plant. The economizer tubes are surrounded by flue gas domain, and these flue gases are entering from the bottom, passing over the tubes and leaving the domain from upper side.

Now, this above geometry was meshed (refer Fig. 5) and solved with the actual boundary condition of thermal power plant to find out the velocity (refer Fig. 6) and temperature distribution (refer Fig. 7) in economizer and identify the region where velocity exceeds the limits. These figures show that the temperature and velocity near the bends are maximum due to reduced flow area; hence, erosion takes place. 


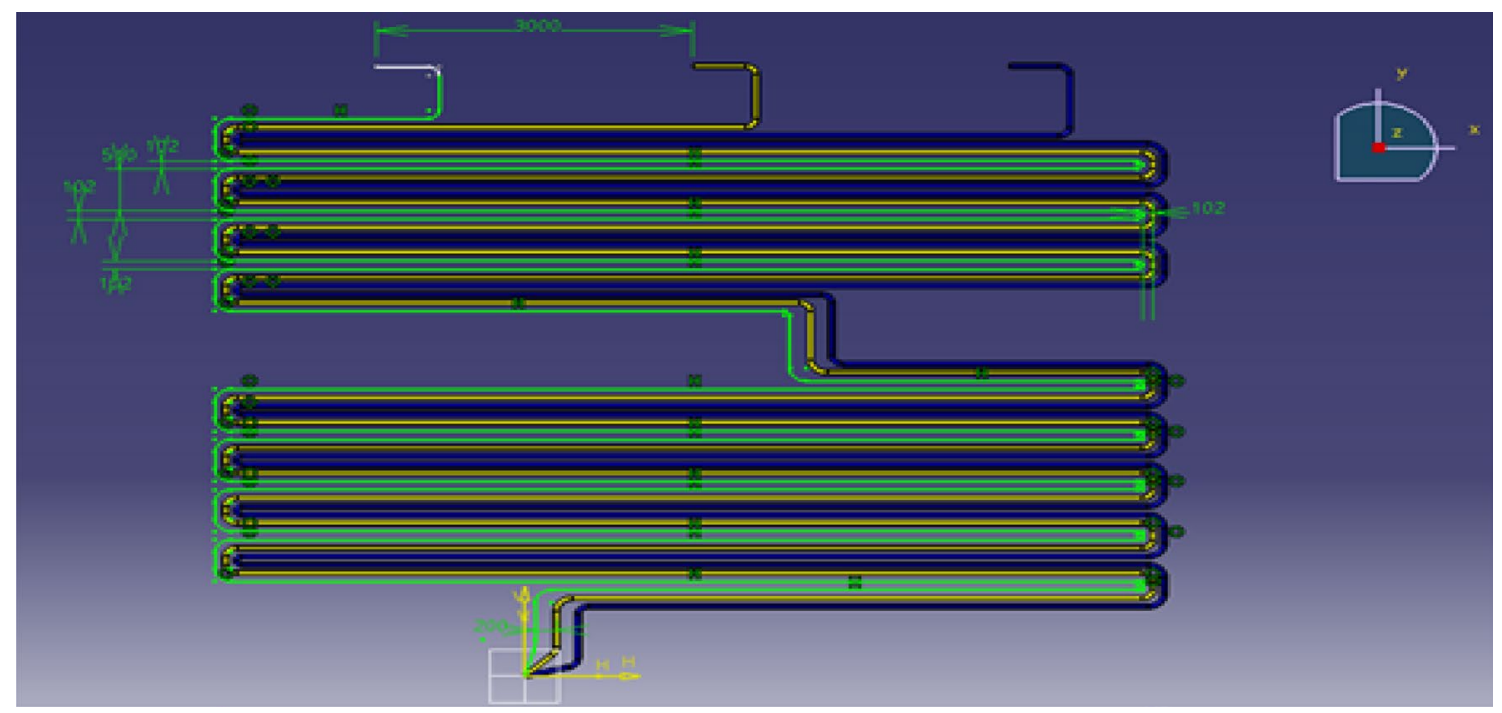

Fig. 3 2-D model of economizer

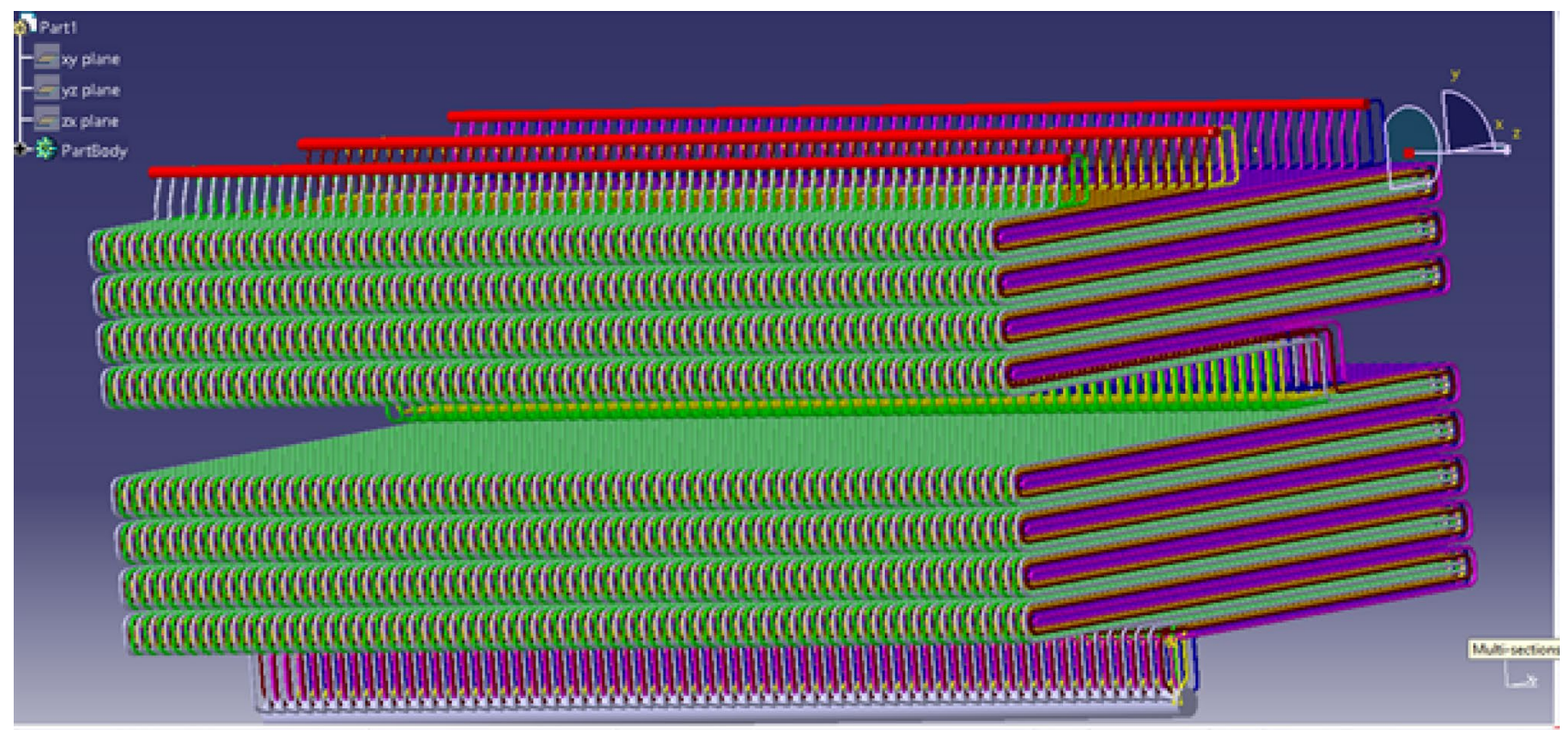

Fig. 4 3-D model of economizer

Figure 8 shows the width and height of a baffle placed in economizer to decrease the erosion by reducing the velocity. It was found that the lowest velocity of flue gases occurs in economizer at width $135 \mathrm{~mm}$ and height $155 \mathrm{~mm}$.

The velocity contour and temperature contour with baffle plates are uniformly distributed as shown in Figs. 9 and 10 , respectively. So, the failure due to erosion can be minimized with the help of baffle plates. This is very useful to increase the availability of economizer. Figure 11 also shows that velocity distribution is much better than previous velocity distribution.

\section{Results}

Failure rate influences the availability of the system, and that can be improved by decreasing the failure rate. Boiler tube failure is one of the most critical causes (maintenance data) for low availability of waste gases heating system. Economizer is identified as a main crucial equipment in this system. For observing the temperature and velocity distribution flow of flue gases in the economizer, velocity and temperature contours were drawn. Similarly, for temperature and velocity contour, CFD analysis was done,

\section{SN Applied Sciences}




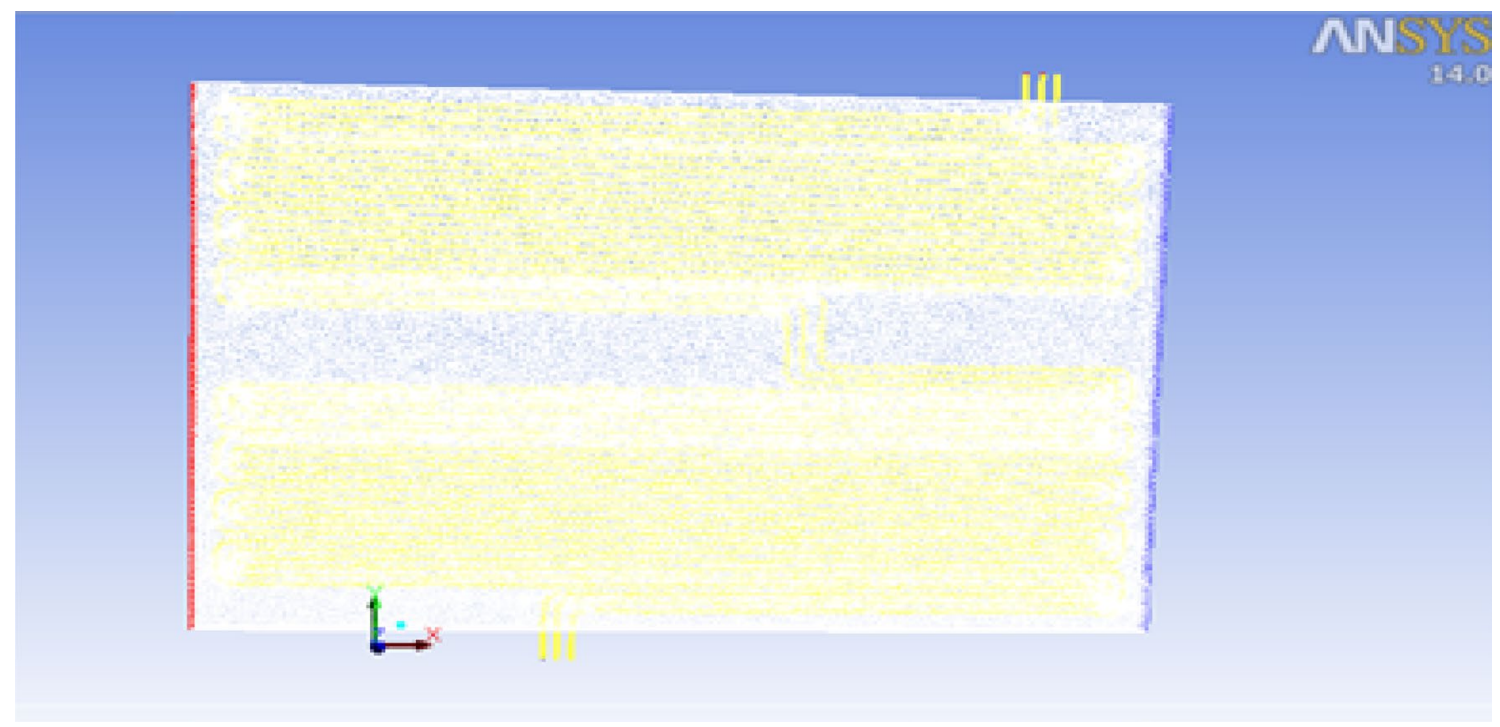

Fig. 5 Meshing of economizer
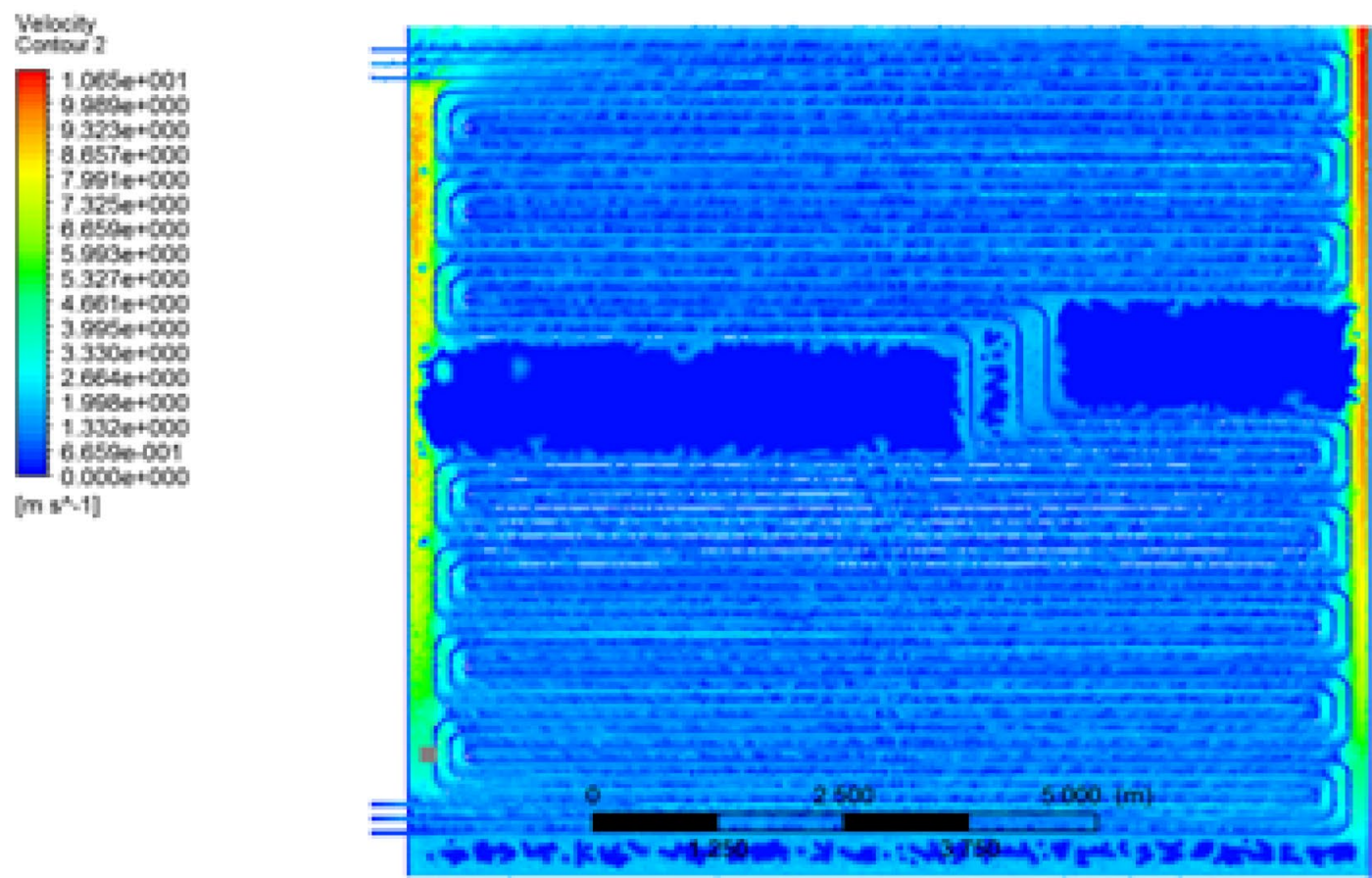

Fig. 6 Velocity distribution in economizer

which shows that the velocity and temperature at the corners on both side were very high. For reducing the erosion due to high velocity and overheating due to high temperature, it was suggested to introduce a baffle plate. This plate was placed in economizer to optimize the velocity and temperature.

\section{Conclusion}

The performance evaluation of waste gases heating system has been done with the help of simulation modeling. Table 3 shows the variation in the system performance with the variation in failure and repair rates of its different components. The various availability levels (Av.) for different combinations of failure and repair rates were also 

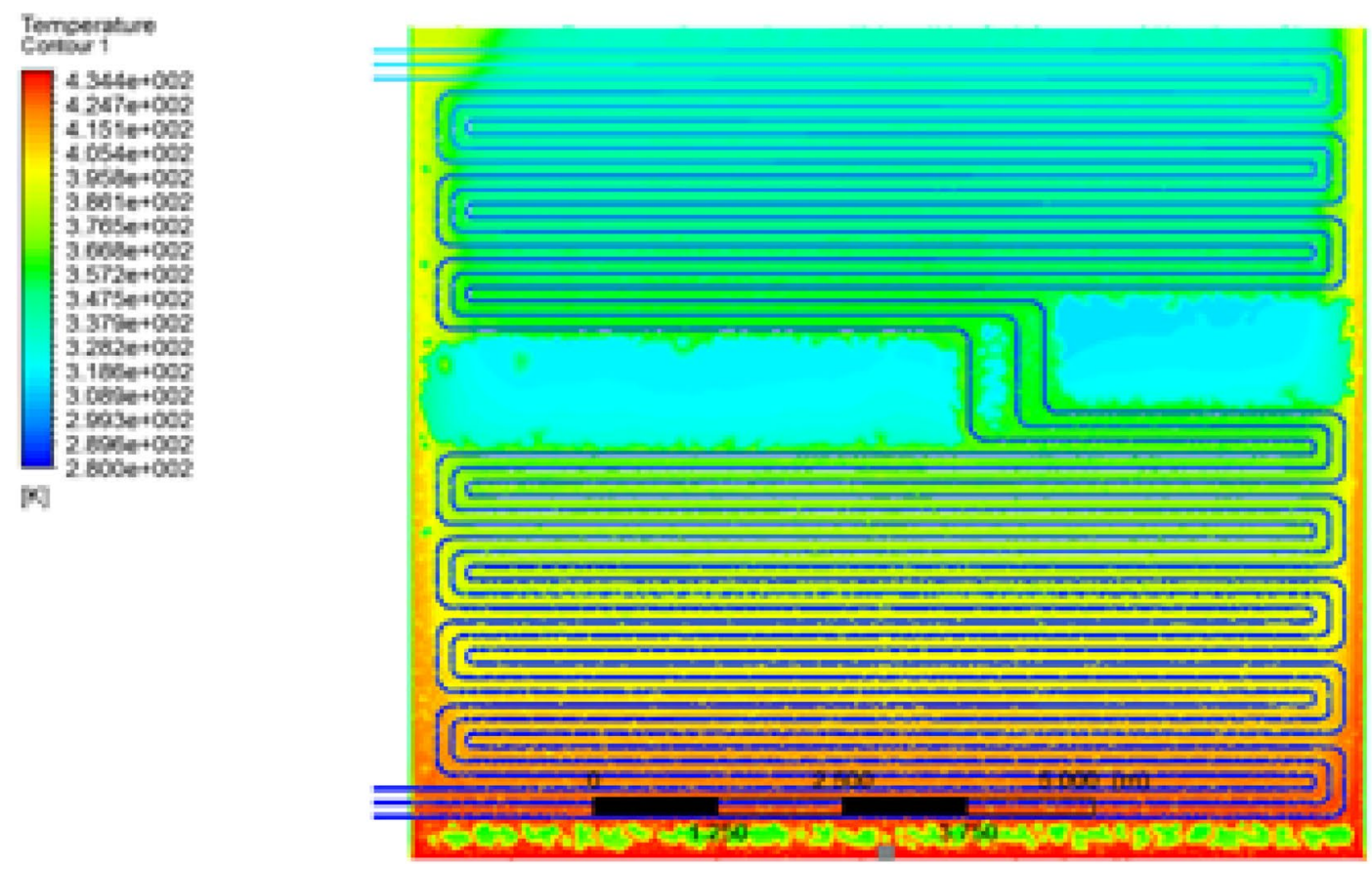

aNSSYS

Fig. 7 Temperature distribution in economizer
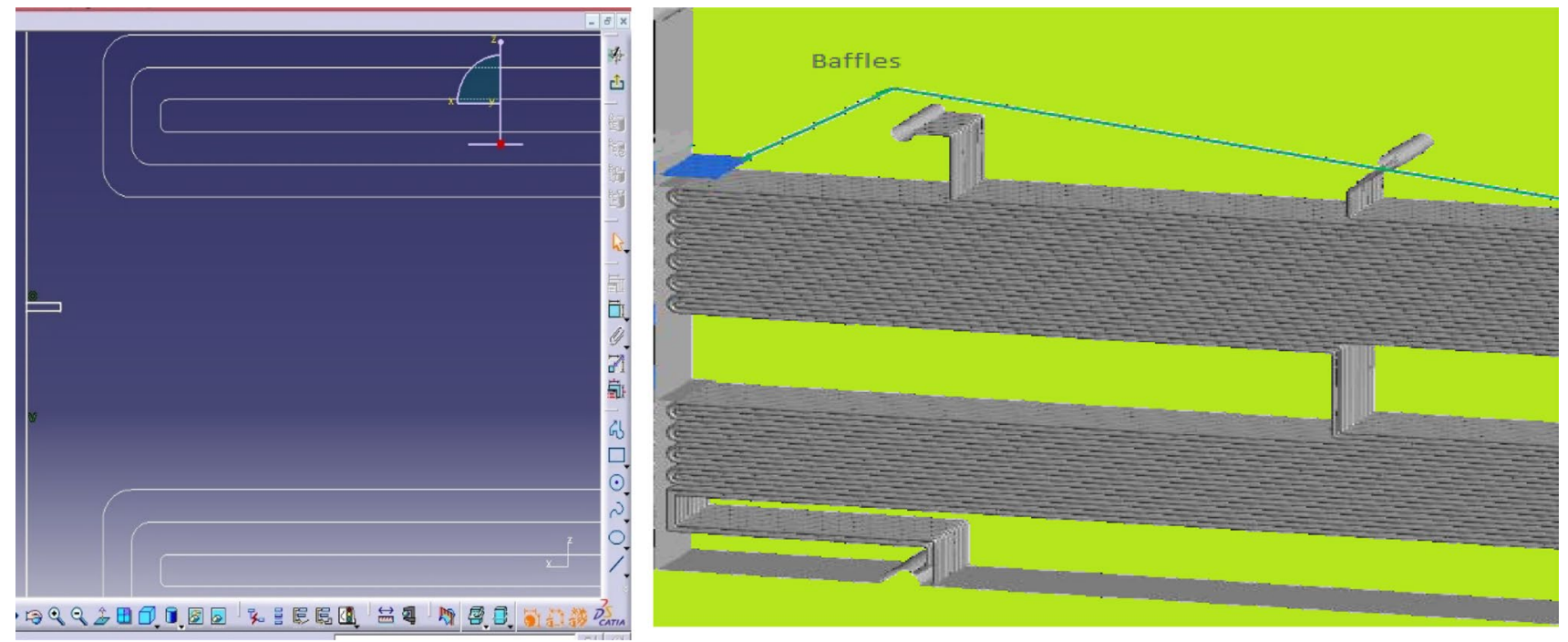

Fig. 8 Baffle plate in economizer

calculated and found that availability of system decreases appreciably as failure rate increases. To improve the availability of the system, it becomes essential that reduces the significant causes of failure. Boiler tube failure is identified as a major critical failure, and the erosion in economizer due to high-velocity waste gases (flue gases) at bends is playing a major role in boiler tube leakages. The erosion has been reduced by introducing a baffle plate at the ends of economizer tubes so that the failure rate and availability of the plant can be minimized and maximized respectively. 


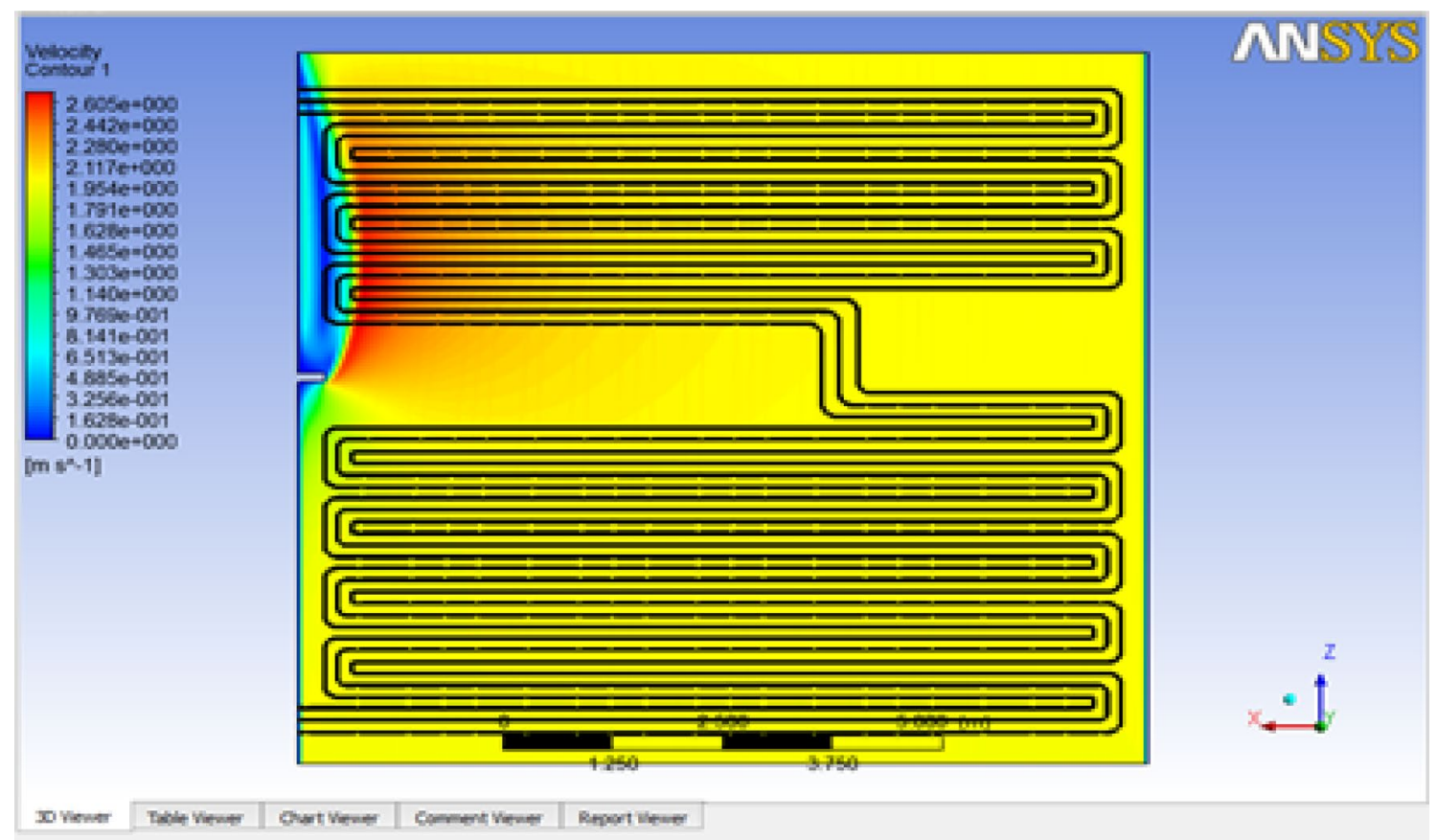

Fig. 9 Velocity distribution with baffle plate in economizer

Fig. 10 Temperature distribution with baffle plate in economizer

Fig. 11 Comparison of velocities in economizer
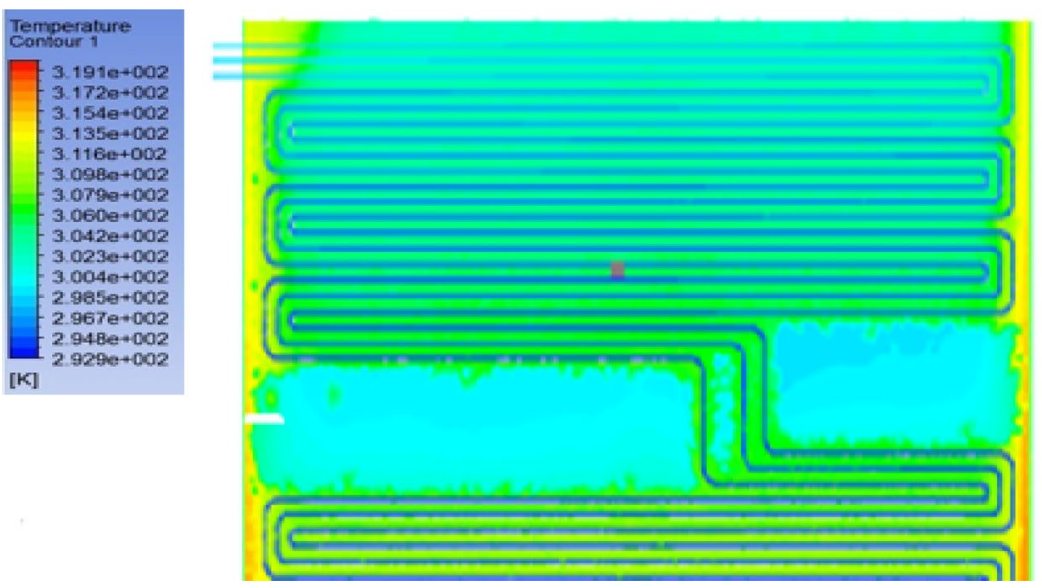

UUNМДI

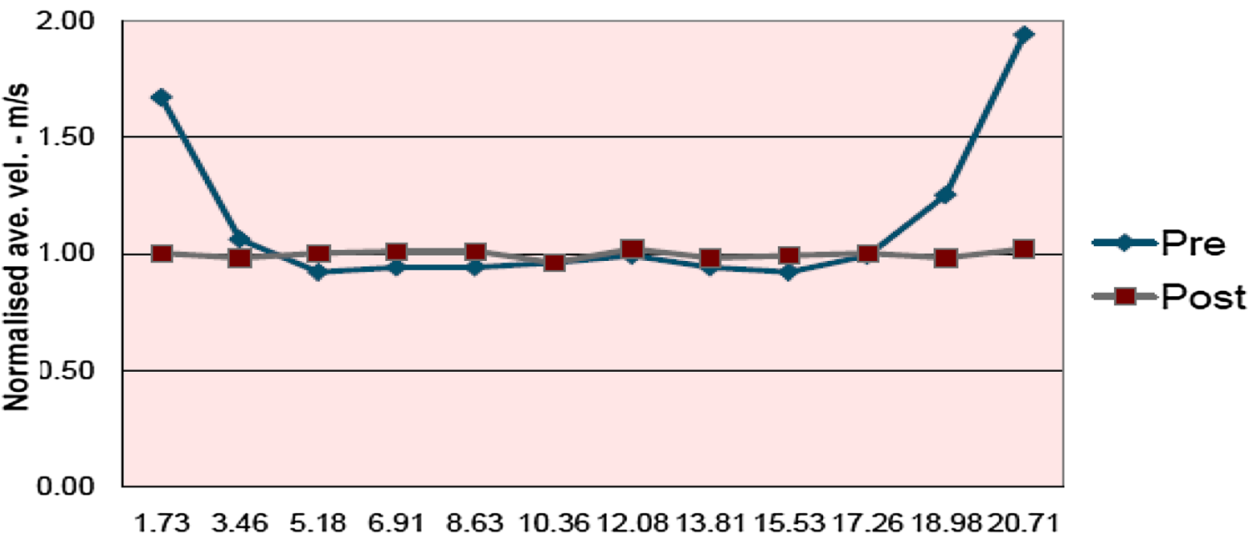

SN Applied Sciences A SPRINGER NATURE journal 
In this way, the overall performance of thermal power plant has been improved.

Acknowledgements The authors are very thankful to the plant management of Deenbandhu Chhotu Ram Thermal Power Plant located at Yamuna Nagar in Haryana, for granting the permission of plant visits and also for informative discussions with staff, engineers and maintenance personnel to attain optimum level of availability of the system concerned.

\section{Compliance with ethical standards}

Conflict of interest The authors declare that they have no conflict of interest.

\section{References}

1. Cherry DH, Perris FA (1978) Availability analysis for chemical plants. Chem Eng Prog 74(1):55-60

2. Dai Y-S, Xie M, Poh K-L, Liu GQ (2003) A study of service reliability and availability for distributed systems. Reliab Eng Syst Safety 79(1):103-112

3. Gupta S, Tewari PC, Sharma AK (2008) A performance modeling and decision support system for a feed water unit of a thermal power plant. S Afr J Ind Eng 19(2):125-134

4. Gupta S, Tewari PC, Sharma AK (2009) Reliability and availability analysis of the ash handling unit of a steam thermal power plant. S Afr J Ind Eng 20(1):147-158
5. Gupta P, Singh J, Singh IP (2005) Mission reliability and availability prediction of flexible polymer powder production system. OPSEARCH-New Delhi 42(2):152-167

6. Kumar R (2014) Availability analysis of thermal power plant boiler air circulation system using Markov approach. Dec Sci Lett 3(1):65-72

7. Khanduja R, Tewari PC, Kumar D (2008) Development of performance evaluation system for screening unit of a paper plant. Int J Appl Eng Res 3(3):451-461

8. Lai CD, Xie M, Poh K-L, Dai Y-S, Yang P (2002) A model for availability analysis of distributed software/hardware systems. Inf Softw Technol 44(6):343-350

9. Kumar P, Tewari PC, Khanduja D (2017) Six Sigma application in a process industry for capacity waste reduction: a case study. Manag Sci Lett 7:423-430

10. Kumar P, Khanduja D, Tewari PC (2017) Maintenance strategy for a system of a thermal power plant. Int J Oper Quant Manag 23(1):101-118

11. Kumar P, Tewari PC, Khanduja D (2016) Maintenance priorities for a repairable system of a thermal power plant subject to availability constraint. Int J Perform Eng 12(6):561-572

12. Sabouhi $H$, Abbaspour A, Fotuhi-Firuzabad $M$, Dehghanian $P$ (2016) Reliability modeling and availability analysis of combined cycle power plants. Int J Electr Power Energy Syst 79:108-119

13. Yadav OP, Singh N, Chinnam RB, Goel PS (2003) A fuzzy logic based approach to reliability improvement estimation during product development. Reliab Eng Syst Safety 80(1):63-74

Publisher's Note Springer Nature remains neutral with regard to jurisdictional claims in published maps and institutional affiliations. 